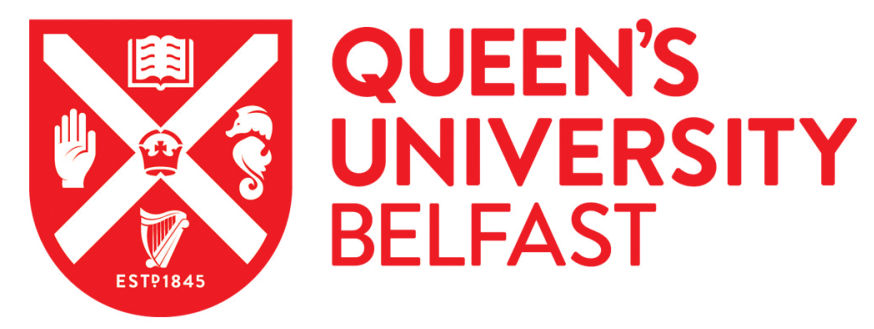

\title{
Comparative investigation of the spatial distribution of past weathering impacts on sandstone masonry
}

Johnston, B., McKinley, J., \& Warke, P. (2019). Comparative investigation of the spatial distribution of past weathering impacts on sandstone masonry. Geomorphology, 324, 25-35.

https://doi.org/10.1016/j.geomorph.2018.09.022

\section{Published in:}

Geomorphology

\section{Document Version:}

Peer reviewed version

\section{Queen's University Belfast - Research Portal:}

Link to publication record in Queen's University Belfast Research Portal

\section{Publisher rights}

Copyright 2018 Elsevier

This manuscript is distributed under a Creative Commons Attribution-NonCommercial-NoDerivs License

(https://creativecommons.org/licenses/by-nc-nd/4.0/), which permits distribution and reproduction for non-commercial purposes, provided the author and source are cited.

\section{General rights}

Copyright for the publications made accessible via the Queen's University Belfast Research Portal is retained by the author(s) and / or other copyright owners and it is a condition of accessing these publications that users recognise and abide by the legal requirements associated with these rights.

Take down policy

The Research Portal is Queen's institutional repository that provides access to Queen's research output. Every effort has been made to ensure that content in the Research Portal does not infringe any person's rights, or applicable UK laws. If you discover content in the Research Portal that you believe breaches copyright or violates any law, please contact openaccess@qub.ac.uk. 


\title{
Comparative Investigation of the Spatial Distribution of Past Weathering Impacts on
}

\section{Sandstone Masonry}

\author{
Brian Johnston, Jennifer McKinley and Patricia Warke
}

\section{Correspondence to BJohnston16@qub.ac.uk}

Keywords: Sandstone, Salt Weathering, Variograms, Geostatistics, Weathering Legacies

\begin{abstract}
Inspection of the deterioration of both natural outcrops and historical built stone facades reveals that patterns of disruption are not uniform, indicating the influence of material and environmental properties. Sandstones have a spatial variability in weathering response. For this reason, geostatistical techniques have been applied to studies of sandstone properties, mineralogical and structural, that influence susceptibility to decay. For this study, a comparative analysis of permeability data acquired from a 'quarry fresh' stone and a weathered sample is undertaken.
\end{abstract}

The depositional processes that resulted in the formation of sandstone also create structures of spatial variation such as laminations or larger bedding planes within the material. Using geostatistical techniques, the permeability variance observed within 'quarry fresh' blocks of sandstone indicates the subsampling of larger geological structures when cut from the quarry face. Once blocks have been emplaced within a building they will be subjected to the increased stress of the urban environment. These conditions result in exacerbated weathering through processes such as salt and chemical weathering. Weathering can alter material properties such as permeability with the creation of a secondary permeability produced by the opening pores and alteration of pore connectivity. Through the application of geostatistics in the analysis of permeability data observed from the weathered block, variography reveals the presence of smaller scale structures. This suggests that alteration of the sandstone's permeability has led to the creation of new weathering structures within the stone, overwriting the initial sedimentary structures. 
These weathering related structures will affect both the magnitude and spatial distribution of permeability within the weathered block. The interconnected pathways of permeability, created by past weathering, facilitate the migration of moisture and salts in solution through the substrate. This work has demonstrated that through a geostatistical approach with the application of co-kriging, these potential moisture pathways can be identified and visualised.

\section{Highlights (3-5, 85 Characters Each)}

- Structures can be observed within the variance of permeability using geostatistics.

- Observed variogram structures indicate the block is sampling sedimentary features.

- Alteration of permeability through weathering overwrites sedimentary structures.

- Co-Kriging is used to model conduits for moisture movement through a weathered block.

\section{Introduction and Background}

Sandstone has historically been the material of choice in the construction of culturally significant buildings, with its selection for each structure based upon its versatility and aesthetics (Fitzner and Heinrichs 2002, Turkington and Paradise 2005). These appealing qualities of the stone are the result of the intrinsic structure and the mineralogy of the material (Smith et al. 2008, Muir et al. 2006). The same characteristics and their spatial variability may influence the initial deterioration of the material. Evidence of spatial variability can also be observed in the colouration and texture of sandstones, such as the large-scale bedding features or finer laminations across quarry faces (McKinley et al. 2012). However, even visually homogenous stone can be heterogenous when considering the structure or cementing of the material. The inheritance of such characteristics created during formation and the susceptibility of the material's properties to change under environmental stresses that, in part, determine the stone's longevity within the built environment (Turkington 1996, Inkpen et al. 2004, Di Benedetto 2015; Goudie 2016). 
However, change is an inherent characteristic for stone (McCabe et al. 2015). Past alteration of the material properties through weathering can have an influence upon the contemporary deterioration processes and their spatial distribution across the block surface (Turkington and Smith 2004, André et al. 2011). One property, commonly used as part of studies observing material alteration associated with decay, is permeability, the capacity of fluid movement within the stone (McKinley and Warke 2007). Permeability can be changed through past weathering processes altering pore shapes and size, creating a secondary porosity (Angeli et al. 2008). A comprehension of the nature of the spatial distribution of alteration will aid in the development of an understanding of weathering patterns across the block, and ultimately the wall, scale. Parallels could also be drawn between patterns of building stone deterioration and the spatial distribution of weathering features across natural rock outcrops, aiding in the comprehension of weathering processes in both settings.

The aim of this project is twofold. Firstly, to investigate how past weathering affects the contemporary spatial distribution of permeability in a historical sandstone block. Secondly, to observe the spatial distribution of potential moisture pathways within the block.

\subsection{Urban Weathering and Weathering Legacies}

Within the natural environment, weathering refers to an exogenetic group of mechanical and chemical processes that breakdown rock into smaller constituent components (Yatsu 1988; Summerfield 2013). Under the influence of the anthropogenic conditions found within the urban environment, weathering processes have developed at an accelerated rate (Gomez-Heras and McCabe 2015; Pope and Rubenstein 1999). However, it needs to be noted that alteration is not only surficial, it extends to the maximum depth of moisture ingress within the stone work.

Sandstone masonry within the urban setting is particularly vulnerable to the impact of salt weathering, widely considered to be a dominant weathering process (Smith et al. 2005; Benavente et al. 2001). Salt weathering is not a simplistic process but rather represents a range of physio-chemical reactions occurring within and subsequently altering the pore spaces of the block (Doehne 2002; Goudie and 
Viles 1997; Fitzner 1990). As a result, understanding the developing pathways, facilitating the passage of moisture and salts, is essential to attempts to understanding the deterioration of masonry blocks.

There is a need to develop an understanding of the influence that alteration, resulting from exposure to past environmental conditions, can have upon future deterioration of masonry. The Building Effects Review Group (BERG) (1989) coined the term, 'memory effect', referring primarily to accumulated salts from past environmental conditions that have the potential to exacerbate future weathering (Inkpen 1991; Smith 1994; Viles 2005). Other authors have since used the term weathering legacies, referring to the accumulated material alterations that have occurred post-emplacement. (McCabe et al. 2007; Gomez-Heras et al. 2009; McCabe et al. 2015). Properties of the rock fabric resulting from the depositional environment and diagenetic processes can be referred to as inheritance effects (Warke 1996). The amassing of these past influences will affect the strength of the material and the accumulated stresses acting upon the blocks (McCabe et al. 2007).

\subsection{Geostatistics and permeability}

As the migration of moisture and associated salts is linked to the spatial variations of the stone's material properties, it is essential that an understanding of characteristic variability is developed (Corbett et al. 1993; Beggan et al 1996). Gas/ air permeametry provide a rapid and non-destructive technique for measuring permeability across rock outcrops (Goggin 1993). However, due to the size of the probe permeameter's aperture and time requirement of sampling a sufficiently dense dataset, it is not feasible to measure at the required density to represent the spatial variability of properties present in natural stone (Carey and Curran 2000; McKinley et al 2006). It is therefore necessary to apply a geostatistical approach to the estimation and simulation of values to 'fill the spaces' between known sample points. Through such techniques, geostatistics can be used to assess the heterogeneity and anisotropy of porous masonry (Grover et al. 2016).

Unlike other interpolation techniques such as inverse distance weighting, through the application of geostatistics it is possible to minimise the effect of smoothing out important features of the material 
through the retention of hard 'known' data (Zhao et al. 2014). This increases the usefulness of the technique for modelling patterns of spatial variability in geological structures. Sedimentary stone permeability variation has been observed through the use of the experimental variogram in geostatistics (Jensen et al. 1994). Jensen et al. (1996) demonstrated that structures existing at a range of scales will affect the variogram in various ways dependent upon the sampling approach and instrumentation. This work also highlighted the experimental variogram's value as a tool for data analysis. At a larger scale, McKinley et al. (2004) observed the influence of the wider depositional environment upon the variance in permeability values recorded from a series of outcrops.

More recent studies have shown the effectiveness of this approach, both to the assessment of the spatial variability of fresh building materials (McKinley et al. 2006) and in the determination of the spatial variability of structures created through simulated weathering processes (McKinley and McCabe 2010, Buj et al. 2010). McKinley and McCabe (2010) used cross-variograms to demonstrate the presence of spatial correlation between a point on a block surface and corresponding points at increasing depths through a masonry block.

\section{Methodology}

\subsection{Material Description}

Scrabo sandstone or Scrabo stone is a member of the Triassic Sherwood Sandstone Group (SSG), lain down in a fluvial environment with periodic aeolian influences (Buckman et al. 1997; Smith et al. 1991). The result of this depositional heritage is that the substrate is spatially variable in terms of the size of grains and subsequent pore sizes (Table 1). Two blocks of Scrabo sandstone were chosen for this study. Scrabo sandstone's versatility for construction, aesthetic properties and local availability made it an appealing building stone in the Belfast area during the city's rapid urban expansion in the 19th Century (Curran et al. 2010). One such building was the Crescent Arts Centre (CAC), the source of the recovered historical block discussed in this paper, located in the south of the city. Belfast's expansion at that time, was rapid, driven by industrialisation relating to the city's position as a 
prominent harbour and shipyard. This meant that the stones within these buildings were exposed to high levels of pollutants and marine salts since their emplacement. In recent years, the concentration of pollutants within the Belfast urban area has remained higher than in other cities in the UK (Cooke and Gibbs 1995).

Table 1. Properties of Scrabo sandstone

\begin{tabular}{l|c} 
& Scrabo Sandstone \\
\hline \hline Grain Size * & Medium (range 0.1 - 0.5 mm) \\
Cementing * & Clay Minerals (smectites), actinolite and Talc (approx. 10\% wt.) \\
Porosity (\% vol.) ** & $20-25$ \\
Permeability (mD) * & $5-1500$ (mean 500) \\
Saturation Coefficient * & 0.7 \\
*adapted from Smith et al. 2002 & \\
** Acquired through Mercury Intrusion Porosity Testing
\end{tabular}

Scrabo sandstone exhibits characteristic well-defined laminations and bedding, resulting from variations in mineralogy, structure and texture (Warke and Smith 2000). Whilst these properties are partly due to depositional processes and burial diagenesis, past contact diagenetic processes, resulting from the intrusion of igneous sills, have played a part in the material's development (McKinley et al. 2001). The magnitude of this process was dependent upon the proximity of the dykes and sills, meaning that there is a strong spatial component to the variation in properties across the quarry. The south face of the quarry was the location used for the recovery of the block of 'fresh' sandstone and is the likely original source of the recovered historical block at the time of the construction.

\subsection{Sample Preparation}

The first of the blocks acquired for this study is a historical block from the Crescent Arts Centre, recovered during restoration work in 2009. This block had been exposed for approximately 114 years. 
The other 'Quarry Fresh' block, was recovered from the nature reserve at the disused Scrabo Quarry, with permission from the Northern Ireland Environment Agency. 'Quarry fresh' refers to the material being recently removed from the quarry and then cut into a regular block of $10 \times 10 \times 10 \mathrm{~cm}$ in dimension, removing the original surface material. Whilst within the quarry the material will have been subjected to 'natural' weathering processes, like any exposed outcrop of stone, however the conditions of the urban environment were not present to exacerbate the process.

The 'quarry fresh' block was cut into slices from a selected 'exposed front' face back to the rear of the block. The designation of these front and rear faces was to facilitate orientating the 3D dataset as if the block was emplaced within a wall. Slices were cut to a thickness of $1 \mathrm{~cm}$, which resulted in 9 slices due to material loss from the blade thickness. The historical block was too friable to cut in slices from the weathering front to the back of the block, instead the slices were cut through the substrate, perpendicular to the front. This decision was made following discussion with and recommendation from Joanne Curran (2006 - to present, personal communication), the lead geologist with industrial partner CONSARC, a building conservation company. The slices were approximately $2.7 \mathrm{~cm}$ in thickness.

Permeability measurements were recorded in a 10 by $10 \mathrm{~cm}$ grid regularly spaced across the surface of each of the slices cut from the study blocks, producing 100 measurement points per slice. It is important to note that all permeability measurements were taken before each rock slice was cut, thus ensuring that the permeability measurements represented the block properties and not just a $10 \mathrm{~cm}$ thick slice of rock. In total 1000 measurement points were recorded for the historical block and 900 readings were taken for the 'quarry fresh' block. Since exact locations were recorded for all permeability measurements for all slices, it was possible to produce three dimensional locations for each of the data points. The measurement data were then re-orientated to provide a block with which allowed direct comparison with the other block. Through this process the author was able to readjust for the different orientation of cutting required to maintain the integrity of the historical block during 
cutting. This methodology was confirmed and approved as the most appropriate approach within funding body (EPSRC) and industrial partner (CONSARC) strategic meetings.

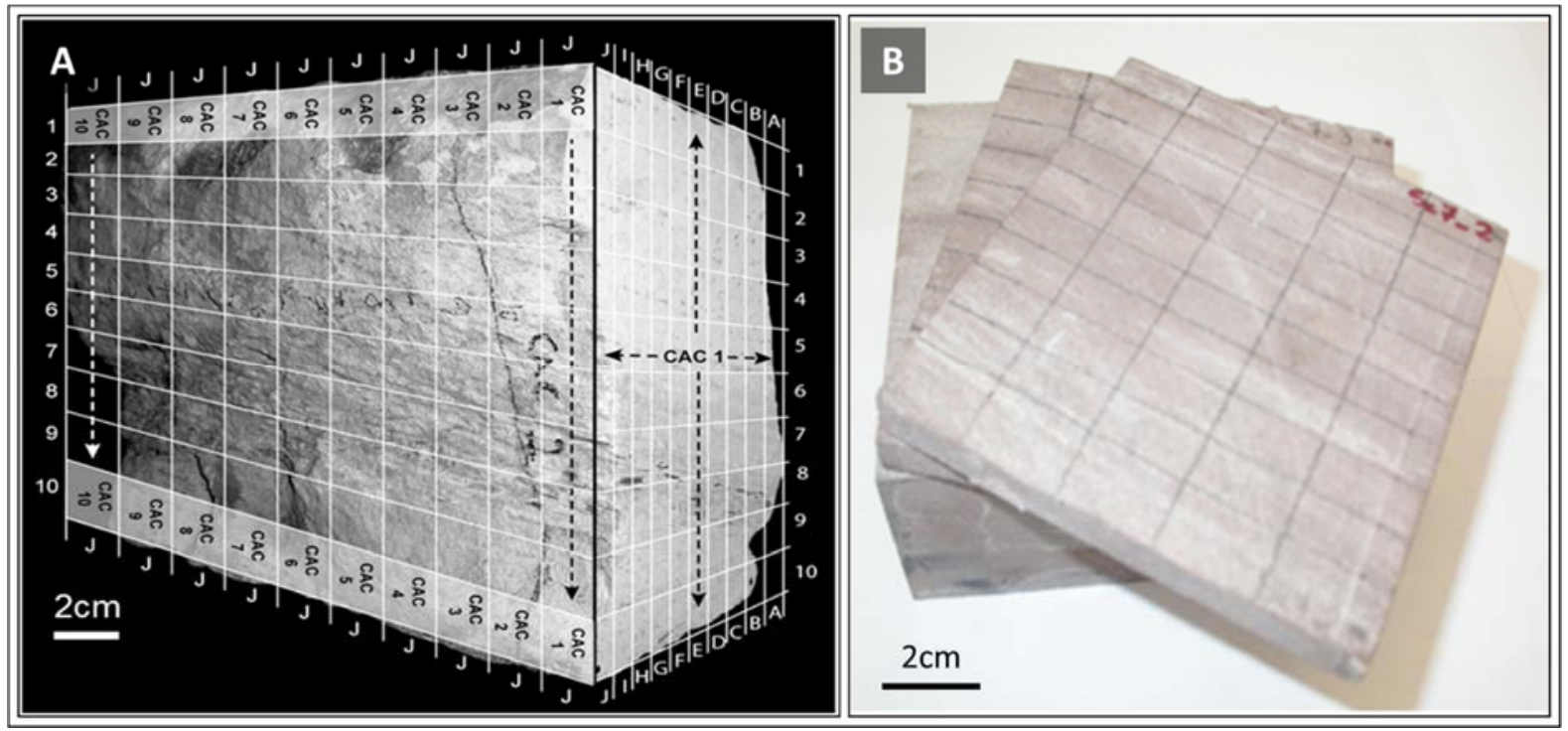

Figure 1. Blocks selected for study marked for slicing to provide internal permeability values, (a)

Historical Block (CAC) (B) Fresh block sample (SC1).

Permeability readings were recorded using a TinyPerm II; Portable Air Permeameter. This piece of equipment makes a seal between an attached rubber nozzle and the stone surface, within which it creates a pressurised volume of air. As air migrates through the stone, the instrument will present the decay in pressure versus time, from which the permeability can be calculated using the pressure decay curve (Jones 1994). The depth of investigation of the probe permeameter, approximately $9 \mathrm{~mm}$, means that all slice thicknesses are suitable for the application of this technique and will have no detrimental impact upon the readings (Rogiers et al. 2013). This provides a measurement in milliDarcies (mD) for each point. 


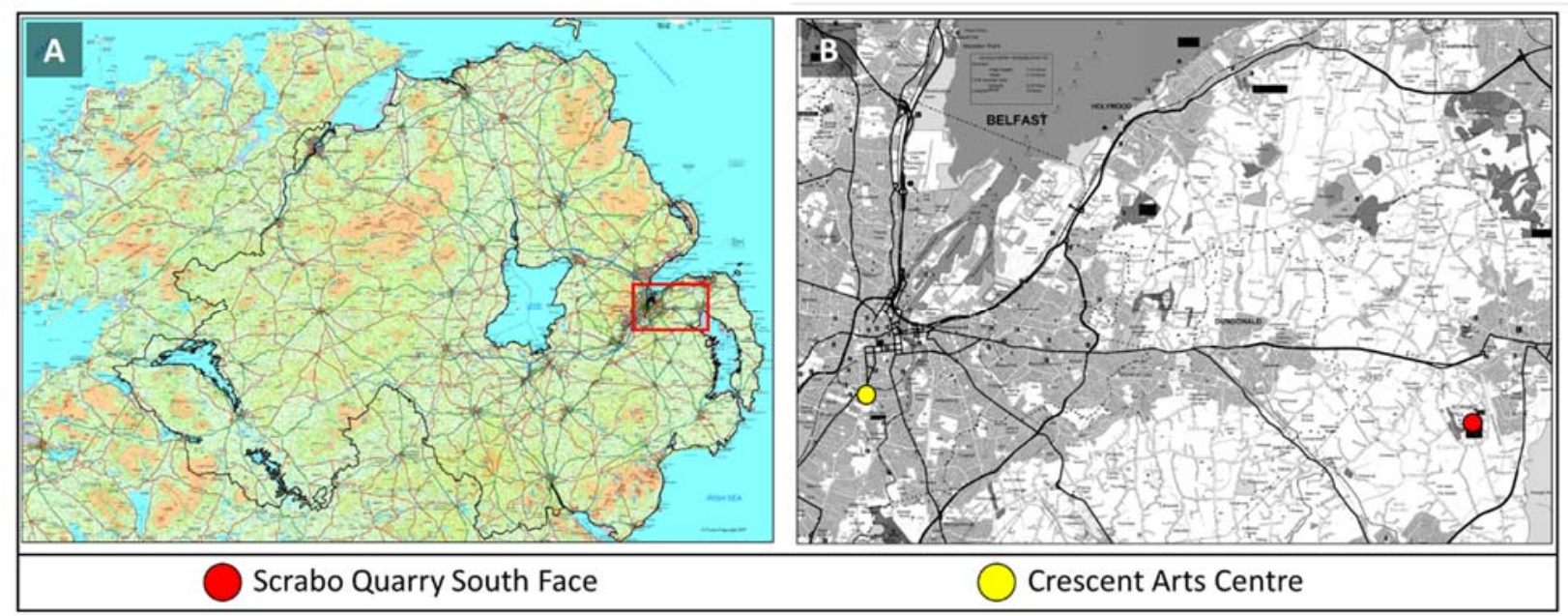

(C) Crown Copyright and Database rights MOU203

Figure 2. (A) Location of Belfast in Northern Ireland and (B) the locations of the Crescent Arts Centre in Belfast and the Scrabo sandstone quarry in the surrounding rural areas.

\subsection{Geostatistical Analysis}

Analysis was undertaken using gstat, a free open source R package (Pebesma 2004). Prior to applying geostatistical techniques, it is recommended to explore summary statistics for both permeability datasets (Oliver and Webster 2015). For geostatistics, an understanding of the centre of the data (e.g. the mean and median) and the spread (e.g. standard deviation and skewness) is essential. Distribution of permeability data is frequently skewed, which can prove to be problematic for variography as, due to its reliance upon variances, it is extremely sensitive to non-symmetrical distributions (McKinley and McCabe 2010). For this reason, it will often be necessary to use log transformed data for kriging when working with datasets measured from the building stones, particularly if the skewness is \pm 1 or if the coefficient of variation is greater than 1 . The transformation of the values to their logarithms prior to kriging helps achieve a normal distribution.

Kriging is applied for the estimation of a desired variable, in this case permeability (Z), at un-sampled locations using measured values from sample points, such as values $z\left(\mathbf{x}_{1}\right), z\left(\mathbf{x}_{2}\right), \ldots, z\left(\mathbf{x}_{n}\right)$ at points $\mathbf{x}_{1}$, $\mathbf{x}_{2}, \ldots, \mathbf{x}_{\mathrm{n}}$ (Oliver and Webster 2015). The use of the 100 measured points from each of the slices 
supports the minimum for computing a reliable variogram by Matheron's estimator (Oliver and Webster 2015). Confirmation of this was established by Kerry and Oliver (2007) through their observation that asymmetry in the distribution of data has a greater increasing effect on the form of the variogram and on the results of cross-validation for a dataset with 100 data.

\subsubsection{Variograms}

The variograms were estimated using the technique provided in McKinley and McCabe (2010). With the estimation of the experimental variogram $\hat{\gamma}(\mathbf{h})$ from paired observations $p(\mathbf{h}), Z\left(\mathbf{x}_{i}\right)$ and $\mathbf{Z}\left(\mathbf{x}_{\mathbf{i}}+\mathbf{h}\right)$, $\mathrm{i}=1,2, \ldots p(\mathbf{h})$ by

$$
\hat{\gamma}(\mathbf{h})=\frac{1}{2 p(\mathbf{h})} \sum_{i=1}^{p(\mathbf{h})}\left\{Z\left(\mathbf{x}_{i}\right)-Z\left(\mathbf{x}_{i}+\mathbf{h}\right)\right\}^{2}
$$

Variograms are modelled onto the ordered set of values, $\hat{\gamma}\left(\mathbf{h}_{1}\right), \hat{\gamma}\left(\mathbf{h}_{2}\right), \ldots$, at lags or spacing distances $\left(\mathbf{h}_{1}, \mathbf{h}_{2}, \ldots\right)$ (Webster and Oliver 2007). Using both automatic and visual fitting, commonly utilised tools in the geostatistian's tool box (Oliver and Webster 2014), it was found that of the types of variography model types available (spherical, exponential, Gaussian, power), spherical provided the best fit for most the variograms. This matches with the established convention of applying this model to data sets describing the properties of rock (Webster and Oliver 2007; McKinley and McCabe 2010). It was subsequently decided that it would be best to use the spherical model for all the variograms to ensure comparability.

As part of these models, three pieces of information is required, the sill, the range and the nugget (Figure 3). A spherical model is a common bounded model which has a maximum variance, known as the sill $\left(C_{0}+C\right)$, the priori variance of the model. The variance may approach this sill, potentially reaching it after a finite distance, the range (a). However, other scenarios representing the presence of second-order stationary processes may exist. For example, fitted variogram models may, upon reaching their maximum variance, subsequently decrease, whilst other fitted models, may oscillate about the priori variance. 


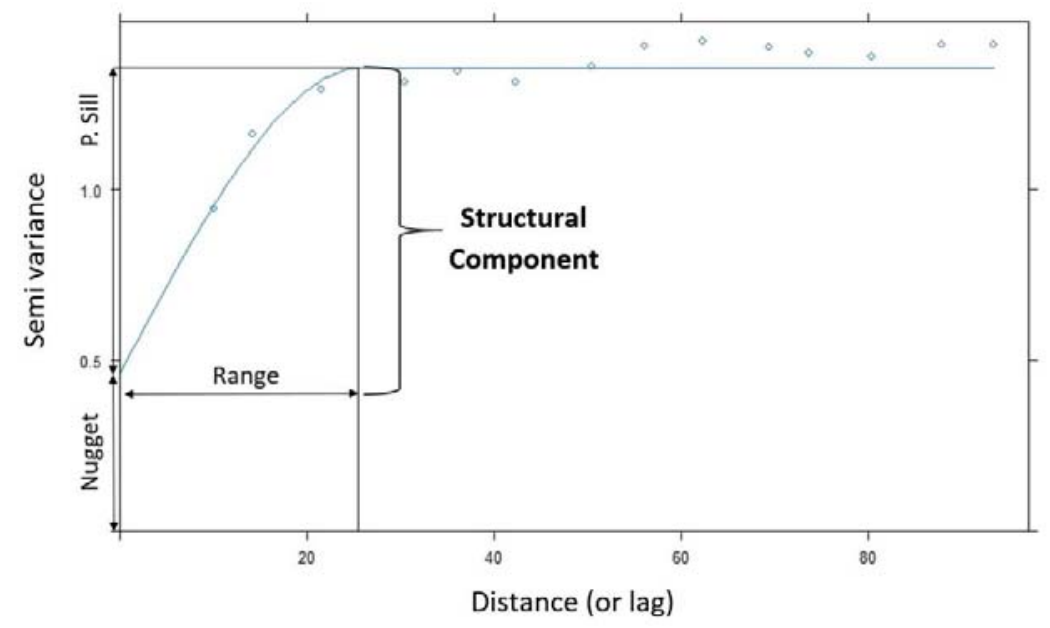

Figure 3. Parameters of the variogram

(adapted from McKinley et al. 2006)

The range, also known as the correlation distance, is the point after which the values are no longer similar, thus becoming independent of each other (McKinley et al. 2006). Ranges have been used to indicate the frequency of parameter variation to determine different structural influences, such as bedding structures (McKinley et al. 2011; Jensen et al. 1996). The range at which the sill value is reached represents the scale of spatial variation of the variable, the scale of the structure.

The nugget $\left(C_{0}\right)$ is linked to the presence of variation of the material at a scale that is finer than the sampling strategy, or the existence of measurement errors. The sill is the sum of the structured component, or partial sill $(C)$, and the nugget effect $\left(C_{0}\right)$. For this reason, the ratio of nugget to sill $\left(C_{0}\right.$ $: \mathrm{C}_{0}+\mathrm{C}$ ) has been calculated to determine the ratio of random to structured variation.

\subsubsection{Kriging}

Kriging refers to a collection of least squares methods of spatial prediction, of which ordinary kriging is the most commonly preferred due to its robustness (Webster and Oliver 2007). Ordinary kriging assumes that the mean is unknown, and is in practice the calculation of a weighed moving average, where the weights are determined by the variogram models and the neighbourhoods assigned to the analysis. McKinley and McCabe (2010) provide a detailed description of the ordinary kriging method. 
Due to the positive skew present in some of the datasets it was decided to apply log transformation to all the data to ensure comparability.

The use of log transformed kriging requires the back-transformation of the output, with consideration for kriging variance, using

$$
\hat{\mathrm{Z}}\left(\mathbf{x}_{\mathbf{0}}\right)=\exp \left\{\hat{\mathrm{Y}}_{\mathrm{OK}}\left(\mathbf{x}_{0}\right)+\sigma_{\mathrm{OK}}^{2}\left(\mathbf{x}_{0}\right) / 2-\psi\left(\mathbf{x}_{0}\right)\right\},
$$

Where, the kriged estimate of the natural logarithms at point $\mathbf{x}_{0}$ is $\hat{Y}_{\mathrm{OK}}\left(\mathbf{x}_{0}\right)$. The output surface was exported to $\operatorname{ArcGIS}^{\mathrm{TM}}$ where it was mapped.

\subsubsection{Co-Kriging}

Co-kriging relies on the spatial correlation, a component of the wider concept of co-regionalisation, between two variables that interest the investigators simultaneously (Webster and Oliver 2007). This has often been utilised when the sampling is insufficient to appropriately determine the presence of a sought-after property, and thus requires supplementing with an additional secondary variable. In this study, the tool will be used to determine the localisation of correlating areas of permeability between slices, with a goal of identifying conduits for moisture migration within the block. The cokriging methodology is provided in greater detail by Webster and Oliver (2007). The first step in the application of cokriging is the estimation of a cross-variogram, $\vee_{u v}(\mathbf{h})$, using the two variables $Z_{u}\left(\mathbf{x}_{i}\right)$ and $Z_{v}\left(\mathbf{x}_{i}\right)$.

$$
\hat{\gamma}_{u v}(\mathbf{h})=\frac{1}{2 p(\mathbf{h})} \sum_{i=1}^{p(\mathbf{h})}\left\{Z_{u}\left(\mathbf{x}_{i}\right)-Z_{u}\left(\mathbf{x}_{i}+\mathbf{h}\right)\right\}\left\{Z_{v}\left(\mathbf{x}_{i}\right)-Z_{v}\left(\mathbf{x}_{i}+\mathbf{h}\right)\right\}^{2}
$$

This cross-variogram will be modelled using the linear model of covariance, this means that any linear combination of variables will be a regionalized variable and the variance needs to be $\leq 0$ (McKinley and McCabe 2010). All the models will have the same number of structures fitted and the same range value will be applied. Additionally, the sills of the variograms must meet the following criteria. 


$$
\left|b_{u v}^{y}\right| \leq \sqrt{b_{u u}^{y} b_{v v}^{y}}
$$

Here, $b_{u v}^{y}$ is the sill of the cross-variogram, while $b_{u u}^{y}$ and $b_{v v}^{y}$ are the sill values of the variogram models produced for the individual attributes. McKinley and McCabe (2010) demonstrated the effectiveness of cross-variograms in the modelling the of regionalisation of permeability values relating to depth within a stone block. Ordinary co-kriging will be applied here forming a linear sum estimating a target variable at a point $\left(\mathrm{x}_{0}\right)$,

$$
\hat{Z}_{u}\left(\mathbf{x}_{0}\right)=\sum_{l=1}^{V} \sum_{i=1}^{n_{l}} \lambda_{i l} z_{l}\left(\mathbf{x}_{i}\right)
$$

where, there are $\mathrm{V}$ variables, $\mathrm{I}=1,2, \ldots, \mathrm{V}$ and the variable to be predicted is $\mathrm{u}$. The value i refers to sites of which there are $n_{1}$ where variable I has been measured.

The weights $\lambda_{\mathrm{i}}$, the non-bias conditions, will satisfy the following,

$$
\sum_{i=1}^{n_{l}} \lambda_{i l}= \begin{cases}1 & l=u \\ 0 & l \neq u\end{cases}
$$

The estimation variance for the desired variable is subject to these weights, which are minimised by the solution of the kriging system.

$$
\sum_{l=1}^{V} \sum_{i=1}^{n_{l}} \lambda_{i l} \gamma_{l v}\left(\mathbf{x}_{i}, \mathbf{x}_{j}\right)+\psi_{v}=\bar{\gamma}_{u v}\left(\mathbf{x}_{j}, \mathbf{x}_{0}\right),
$$

where, $v=1,2, \ldots, V$ and $j=1,2, \ldots, n_{v}$. The calculated weights are feed into equation 12 to estimate the $\mathrm{Z}_{\mathrm{u}}\left(\mathbf{x}_{0}\right)$.

\section{Results and Interpretation}

\subsection{Summary Statistics}


Initial statistical analysis was carried out for each of the slices of the blocks. This included histograms, produced to visualise the statistical distribution of the data. The histograms for slice 1 and slice 6 of the study block are presented in Figure 4.

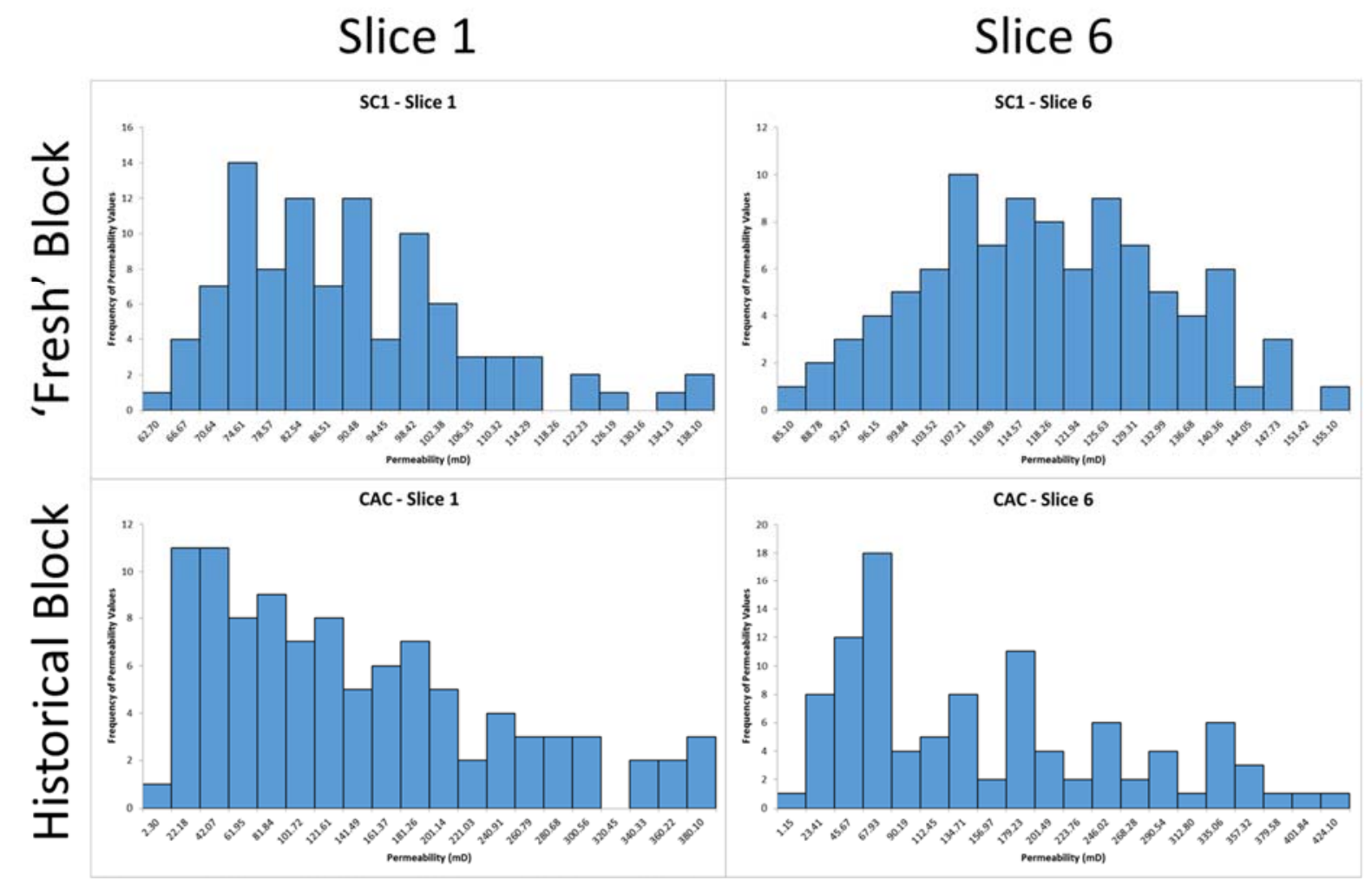

Figure 4. Example histograms produced from the permeability values for slices 1 and 6 for each of the test blocks.

The coefficient of skewness (Table 1) for the 'fresh' block suggests a symmetry to the permeability data. Only Slice 1 demonstrates a positive skewness (1.0). Additionally, the coefficient of variation for the slices is $<0.5$, suggesting a limited heterogeneity in permeability. Visual inspection of the histograms and consideration of the summary statistics suggests that there is limited heterogeneity in the permeability values in the fresh material. The slices of the historical block are positively skewed. The skewness is particularly extreme in the near surface slices, 1.80 and 1.37 in slices 1 and 2 respectively. Visual inspection of the histograms reveals an asymmetric shape, with most points between $30-250 \mathrm{mD}$ and a tail of larger values. 
Table 2. Summary Statistics for the slices of 'fresh' block and historical block

\begin{tabular}{|c|c|c|c|c|c|c|c|c|c|c|c|}
\hline & & & & & & & & & & & \\
\hline \multirow{2}{*}{\multicolumn{2}{|c|}{ Slice }} & \multicolumn{10}{|c|}{ Initial Slice Statistics } \\
\hline & & 1 & 2 & 3 & 4 & 5 & 6 & 7 & 8 & 9 & 10 \\
\hline \multirow{9}{*}{ 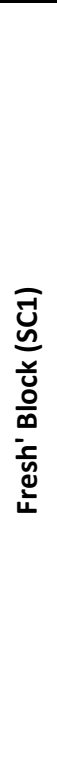 } & Min & 62.7 & 63.9 & 89.7 & 62.5 & 89.1 & 85.1 & 79.0 & 92.5 & 86.3 & I \\
\hline & Lower Quartile & 74.2 & 101.3 & 112.0 & 89.9 & 109.0 & 104.0 & 105.5 & 112.0 & 104.0 & / \\
\hline & Median & 86.2 & 118.0 & 124.0 & 106.0 & 122.0 & 115.0 & 117.0 & 119.0 & 112.5 & / \\
\hline & Upper Quartile & 96.1 & 138.8 & 137.8 & 115.0 & 134.0 & 126.0 & 130.0 & 127.0 & 126.8 & / \\
\hline & Max & 138.0 & 179.0 & 166.0 & 142.0 & 155.0 & 155.0 & 162.0 & 164.0 & 160.0 & / \\
\hline & mean & 87.4 & 119.2 & 124.0 & 102.4 & 121.6 & 116.0 & 118.2 & 120.6 & 116.5 & / \\
\hline & Standard Dev. & 16.2 & 26.1 & 17.4 & 18.4 & 15.8 & 15.4 & 16.2 & 12.7 & 15.9 & / \\
\hline & Skewness & 1.0 & 0.0 & 0.0 & -0.3 & 0.0 & 0.2 & 0.3 & 0.6 & 0.7 & / \\
\hline & CV & 0.2 & 0.2 & 0.1 & 0.2 & 0.1 & 0.1 & 0.1 & 0.1 & 0.1 & / \\
\hline \multirow{9}{*}{ 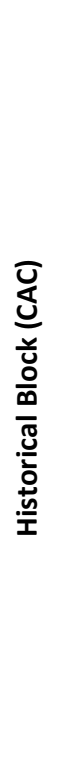 } & Min & 2.3 & 0.3 & 1.0 & 1.2 & 1.3 & 1.2 & 1.5 & 2.5 & 1.7 & 2.1 \\
\hline & Lower Quartile & 49.9 & 53.4 & 52.7 & 39.2 & 59.3 & 53.1 & 53.8 & 70.8 & 61.0 & 54.4 \\
\hline & Median & 103.5 & 117.0 & 103.5 & 122.5 & 113.0 & 119.0 & 108.0 & 128.5 & 122.0 & 106.5 \\
\hline & Upper Quartile & 191.0 & 190.8 & 173.3 & 215.8 & 196.8 & 220.8 & 211.5 & 206.8 & 233.8 & 174.8 \\
\hline & Max & 380.0 & 389.0 & 435.0 & 605.0 & 582.0 & 424.0 & 515.0 & 457.0 & 541.0 & 540.0 \\
\hline & mean & 130.4 & 126.3 & 125.3 & 144.0 & 133.6 & 141.1 & 140.9 & 144.8 & 152.7 & 126.0 \\
\hline & Standard Dev. & 99.6 & 90.2 & 93.3 & 121.7 & 102.3 & 109.2 & 115.1 & 99.2 & 118.8 & 96.7 \\
\hline & Skew & 0.8 & 0.7 & 1.2 & 1.2 & 1.3 & 0.7 & 1.1 & 0.7 & 1.1 & 1.3 \\
\hline & CV & 0.8 & 0.7 & 0.7 & 0.8 & 0.8 & 0.8 & 0.8 & 0.7 & 0.8 & 0.8 \\
\hline
\end{tabular}

\subsection{Variography}

The variography undertaken for the study blocks shows varying scales of structures present based on the spatial variability of the permeability values (variograms for slice 1 and slice 6 are presented in Figure 5). 
The historical block slices show the presence of ranges between 5.7 and $22.1 \mathrm{~cm}$ (table 2). With the largest of these ranges being found in slice 10 at the very rear of the block. Except for this slice the range values are suggestive of observed structures existing at a scale that is fully represented within the limits of the block. The second largest range was $12.2 \mathrm{~cm}$ found in slice 2 (15cm depth) corresponding to the near surface. Fitting of the models to slices 5 and 8 have resulted in models with no nugget effect. However, the inference that this means that the sampling technique has fully captured the finer resolution structures of the material is likely erroneous, given the limitations of the sampling and measurement techniques.

The remaining model's nugget to sill ratios are wide ranging, from $24.47 \%$ to $89.81 \%$, with the largest ratio relating to slice 10 . As mentioned, given the observation limitations it is unsurprising that that considerable unresolved variation exists at the finer scale. Visual inspection of the variograms produced for the slices shows the presence of oscillations in variance about the sill, indicating the presence of periodicity in the data set.

\section{Historical (CAC) Block}

\begin{tabular}{|c|c|c|c|c|c|c|c|c|c|c|}
\hline & Slice 1 & Slice 2 & Slice 3 & Slice 4 & Slice 5 & Slice 6 & Slice 7 & Slice 8 & Slice 9 & Slice 10 \\
\hline Nugget $\left(C_{0}\right)$ & 0.35 & 0.00 & 0.32 & 0.39 & 0.00 & 0.47 & 0.58 & 0.00 & 0.13 & 0.65 \\
\hline Range & 41.37 & 45.11 & 45.00 & 65.45 & 60.77 & 59.46 & 67.87 & 56.75 & 54.79 & 57.25 \\
\hline Sill (C) & 0.88 & 1.35 & 0.80 & 1.15 & 1.27 & 0.80 & 0.73 & 1.30 & 0.95 & 0.49 \\
\hline$C+C_{0}$ & 1.23 & 1.35 & 1.12 & 1.53 & 1.27 & 1.27 & 1.31 & 1.30 & 1.08 & 1.14 \\
\hline$C_{0}: C+C_{0}$ & 0.28 & 0.00 & 0.28 & 0.25 & 0.00 & 0.37 & 0.44 & 0.00 & 0.12 & 0.56 \\
\hline
\end{tabular}

Table 3. Variogram parameters for the Historical Block

The quarry 'fresh' block demonstrates varying range values, between $4.1 \mathrm{~cm}$ and $117.1 \mathrm{~cm}$, dependent upon the slice observed (table 3). The diversity of range values suggests the presence of sedimentary structures at different scales. Whilst some of the fitted models show a structure observable at the block scale, others extrapolate structure beyond the block, and therefore beyond the scale of the 
study. These larger scale features may be associated with the large scale depositional features present across the quarry faces that the blocks have been cut from. If this is the case, then it demonstrates that the blocks when emplaced within the wall represent small sections of the faces from which they have been cut and carry the legacy of an original depositional environment. The range of the nuggetto-sill ratios is $17.42 \%$ to $90.67 \%$, suggesting that the sampling had differing success in capturing the fine detail of the structural elements present. As with the range values, it suggests that with varying slices there are different scales of structures being observed in the datasets.

\section{Fresh (SC1) Block}

\begin{tabular}{|c|c|c|c|c|c|c|c|c|c|}
\hline & Slice 1 & Slice 2 & Slice 3 & Slice 4 & Slice 5 & Slice 6 & Slice 7 & Slice 8 & Slice 9 \\
\hline Nugget $\left(C_{0}\right)$ & 0.02 & 0.05 & 0.01 & 0.00 & 0.01 & 0.01 & 0.01 & 0.01 & 0.01 \\
\hline Range & 213.46 & 136.48 & 70.32 & 41.87 & 41.64 & 469.06 & 42.97 & 588.45 & 919.19 \\
\hline Sill (C) & 0.03 & 0.02 & 0.01 & 0.04 & 0.01 & 0.05 & 0.01 & 0.01 & 0.12 \\
\hline$C+C_{0}$ & 0.05 & 0.07 & 0.02 & 0.05 & 0.02 & 0.07 & 0.02 & 0.02 & 0.13 \\
\hline$C_{0}: C+C_{0}$ & 0.42 & 0.71 & 0.61 & 0.09 & 0.42 & 0.20 & 0.55 & 0.41 & 0.08 \\
\hline
\end{tabular}

Table 4. Variogram parameters for the 'fresh' block 
Slice 1
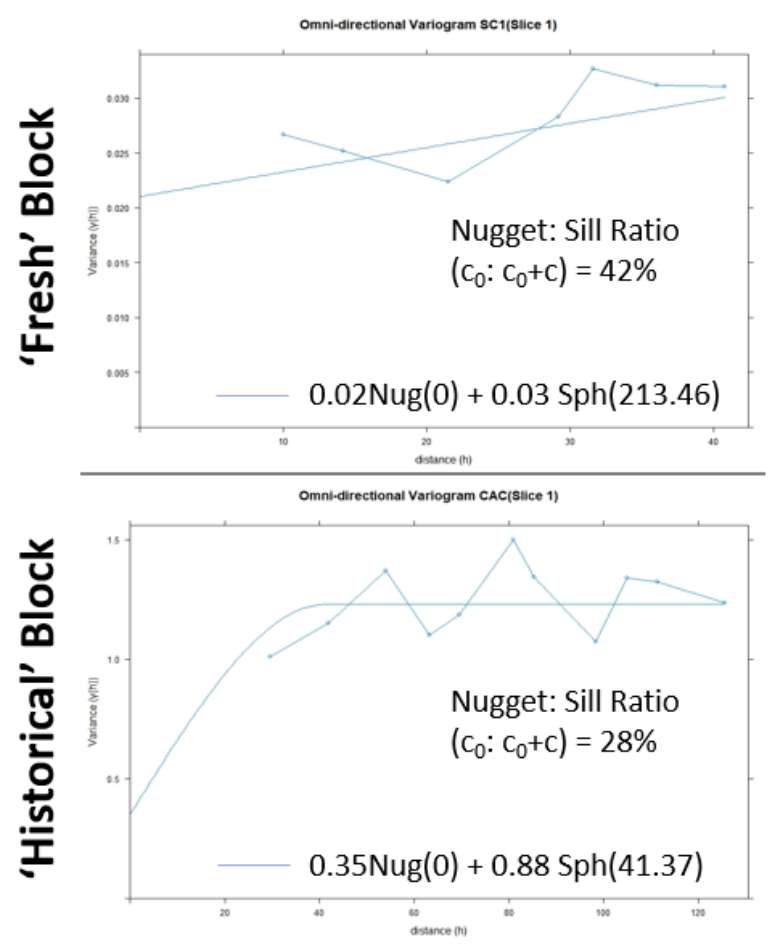

Slice 6

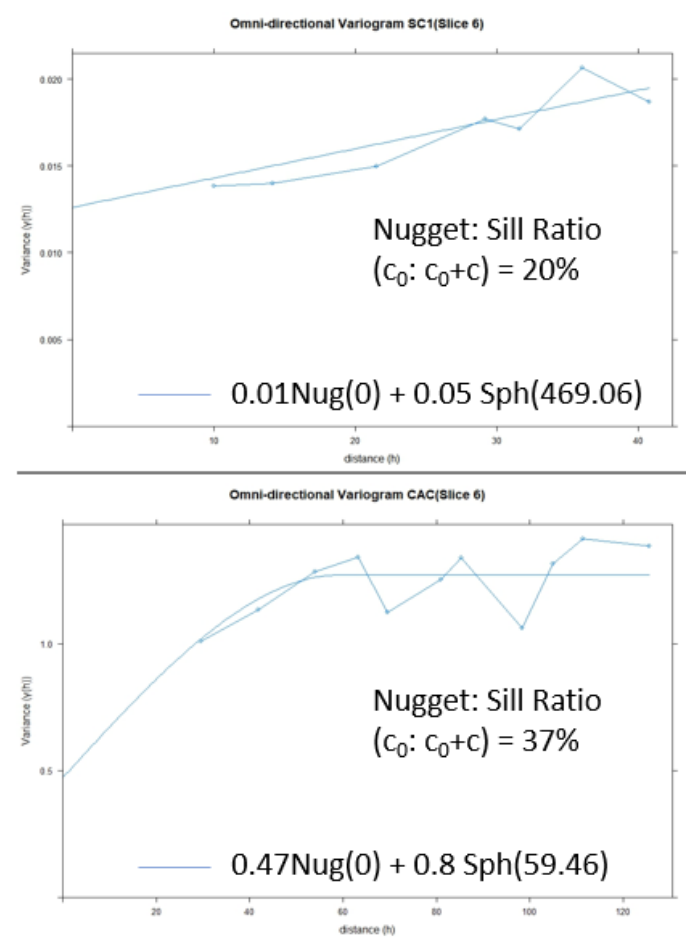

Figure 5. Omnidirectional Variograms of permeability $(m D)$ for slices 1 and 6 of the three experimental blocks.

\subsection{Kriged Surfaces}

Three-dimensional visualisations of the estimated permeability surfaces for both of the blocks are displayed in Figures 7 and 8. Parameters from the modelled variograms were applied to the sample data for kriging. The estimated surfaces identified areas of higher and lower permeability for each of the slices. Examination of the spatial variation of permeability for the historical block data indicates a band of lower permeability present across all estimated surfaces. Examination of the block's geological features shows the presence of a bedding feature at the corresponding location. Away from the bedding plane, spatial variation in permeability is visually more pronounced (higher) and more variable. It is most likely that pathways for moisture ingress relating to the permeability of the material will be found in these locals. 
The estimated permeability surfaces and variograms of the 'fresh' material suggests limited heterogeneity to the spatial distribution of permeability values. The lowest permeability values where observed on the first slice.

\subsection{Cokriging}

Prior to undertaking co-kriging, it was necessary to calculate covariance values between the slices of the blocks. If the covariance values between the slices is a negative number, there is no correlation between the spatial distribution of values and the application of co-kriging is redundant. Inspection of the covariance values for the 'fresh' block revealed that limited covariance was present. The historical block however demonstrates the presence of co-regionalisation between multiple slices.

For illustrating the potential application of co-kriging to the identification of conduits between slices, the data for slices 5 and 6 of the historical block will be used. The covariance of the log transformed values between these slices is 0.6 , indicating a moderate correlation between the two data sets. The cross variogram calculated for these two slices is presented in Figure 6. It shows a bounded spherical spatial structure for the combined model, although it is off from the individual models, supporting the evaluation of this being a moderate correlation. This model was then fed into the kriging equation with the two variables, slice 6 as primary and slice 5 as secondary. Kriging will estimate the permeability for the primary slice using the variables of the secondary slice to supplement the calculation. 


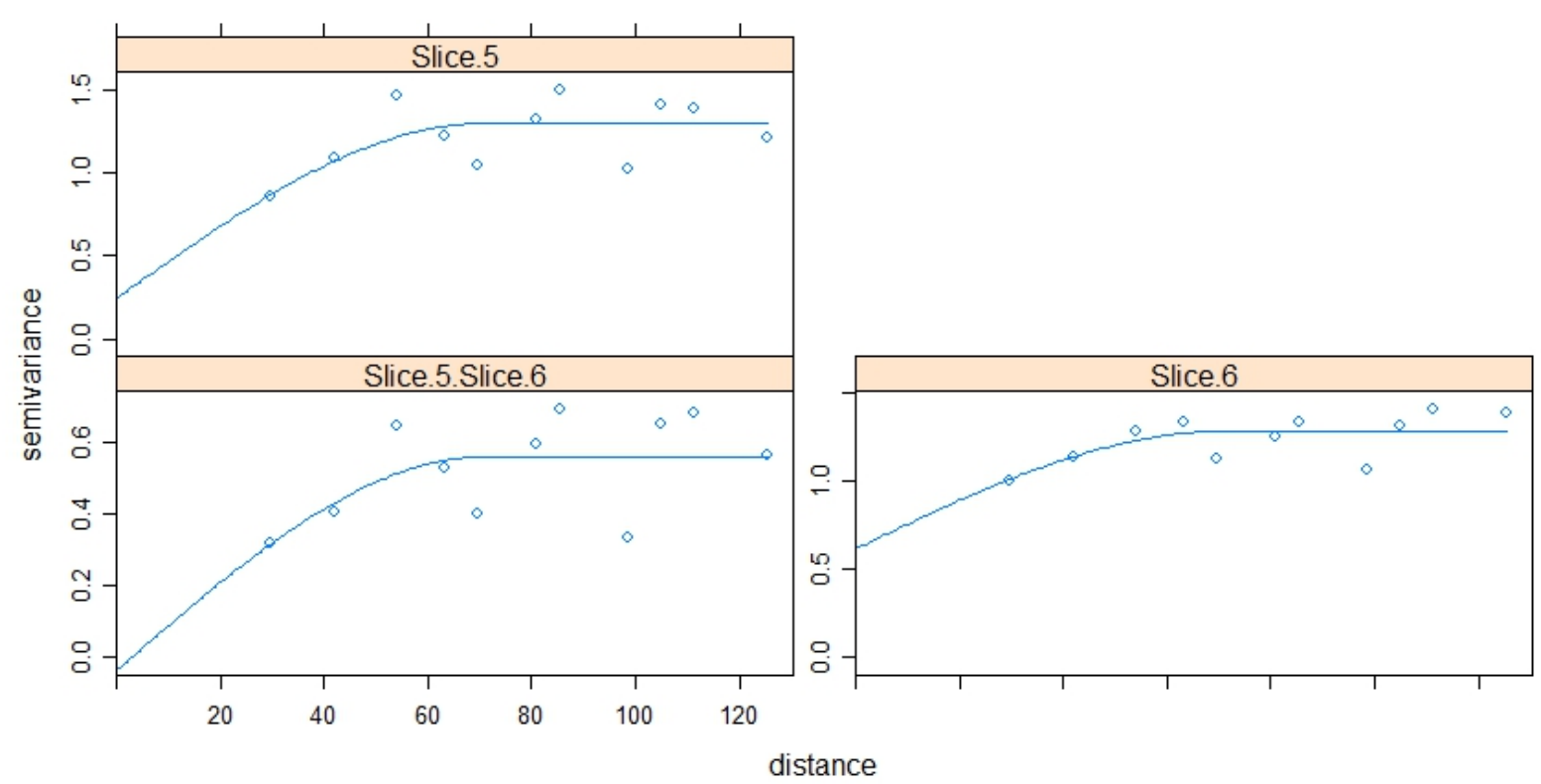

Figure 6. Cross variogram of the permeability values from slice 5 and slice 6 of the historical block.

The resulting structure is modelled using a bounded spherical model

The resulting output is a permeability map for the primary slice with greater estimated permeability values than an ordinary kriging output, where secondary data has indicated the presence of a higher permeability. Similarly, indications of lower permeability values in the secondary data results in a reduced value in sections of the co-kriging output. Areas that are similar in permeability will see little or no change between the ordinary kriging and the co kriging outputs.

\section{Discussion}

The material used in this study represents blocks with a similar origin in terms of sedimentary and diagenetic processes. Yet, it is the degree to which they've been exposed to the urban weathering environment that has defined the different weathering experiences (Gomez-Heras and McCabe 2015). This means that the quarry 'fresh' stone can be used as a point of comparison for the historically weathered material.

\subsection{Large Scale Depositional Features in 'Fresh' Building stone}




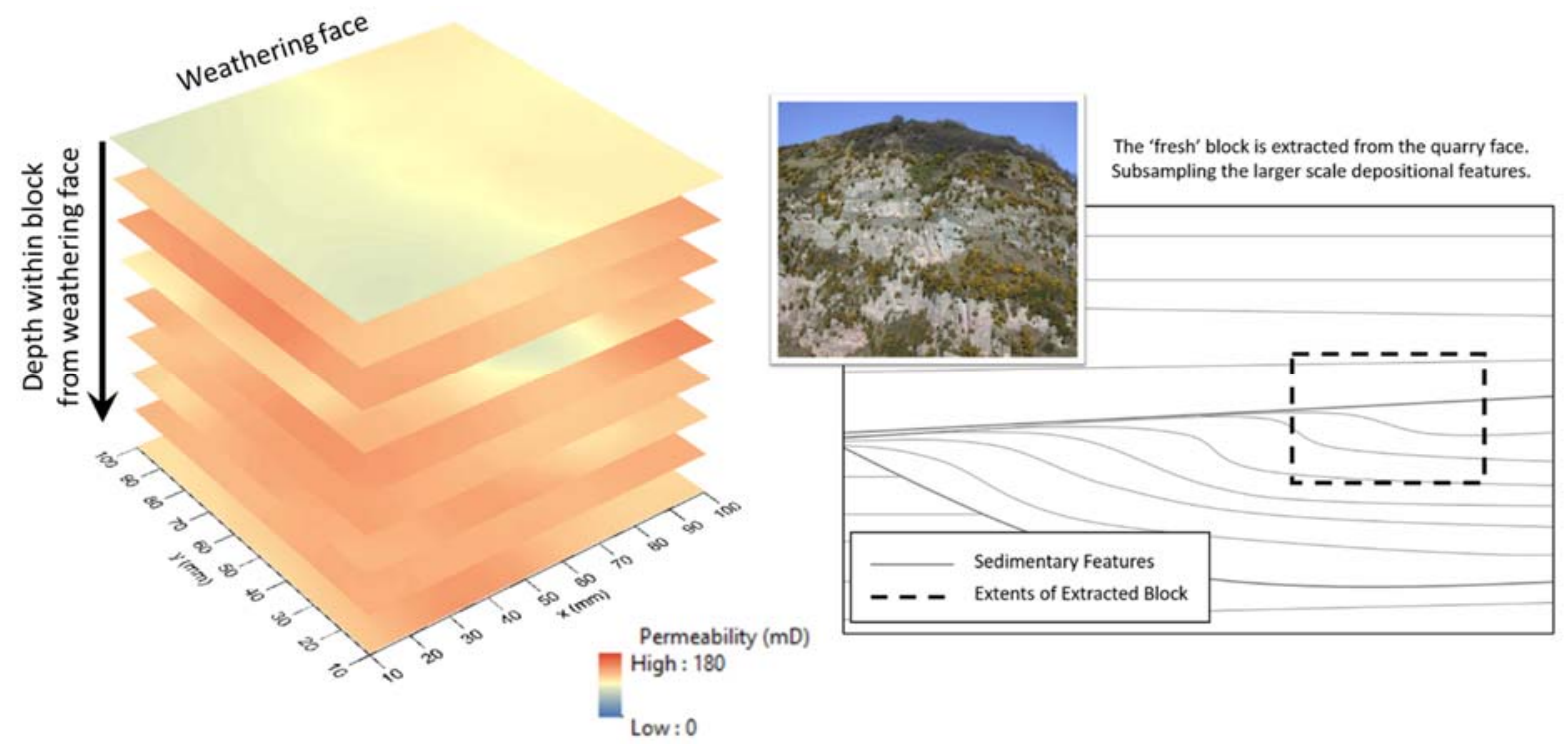

Figure 7. The development of spatial patterns in permeability resulting from the influence of past weathering experiences. The 'fresh' block reveals a large-scale structure associated with the subsampling of the larger depositional features of the quarry face. This has resulted in homogenous permeability across the surfaces of the slices.

The permeability variation of 'fresh' clastic stone types has a strong deterministic component (Jensen 1996). Variograms of the fresh block indicate the presence, in some of the slices, of structures that extend beyond the limits of the measured extent. The extents of measurement have been set by the size of the block. This indicates that a larger structure is being partially sampled in the block. Other slices have variograms that suggest the presence of smaller scale structures that have been fully observed at the measured scale. As this block is 'quarry fresh', it can be concluded that the sources of these structures are the depositional and diagenetic processes that lead to the material's formation, rather than urban weathering alteration.

Laminations and bedding planes are sedimentary features occurring at different scales, resulting in estimated variograms with different structures. Sampling regimes need to be adjusted dependent upon the scale of feature, otherwise it will not be possible to capture the permeability heterogeneity (Jensen 1996). The variety in variogram ranges and nugget-to-sill ratios illustrates either the diversity 
of sedimentary features present within the block or differing effectiveness of the applied sampling techniques for each slice.

In weathering studies focusing on built heritage, it is important to remember that the blocks should not be considered in isolation, but rather as constituent components of the larger structure. However, it is also necessary to remember that when the block is cut from the 'natural' stone of a quarry face it retains a section of the depositional structures and diagenetic characteristics and related variability in permeability. It is these properties that will influence the distribution of salts and ultimately the decay that the block is subjected to (Warke et al. 2006; McKinley and Warke 2007).

\subsection{Block Scale Features within Recovered Historical Stone}

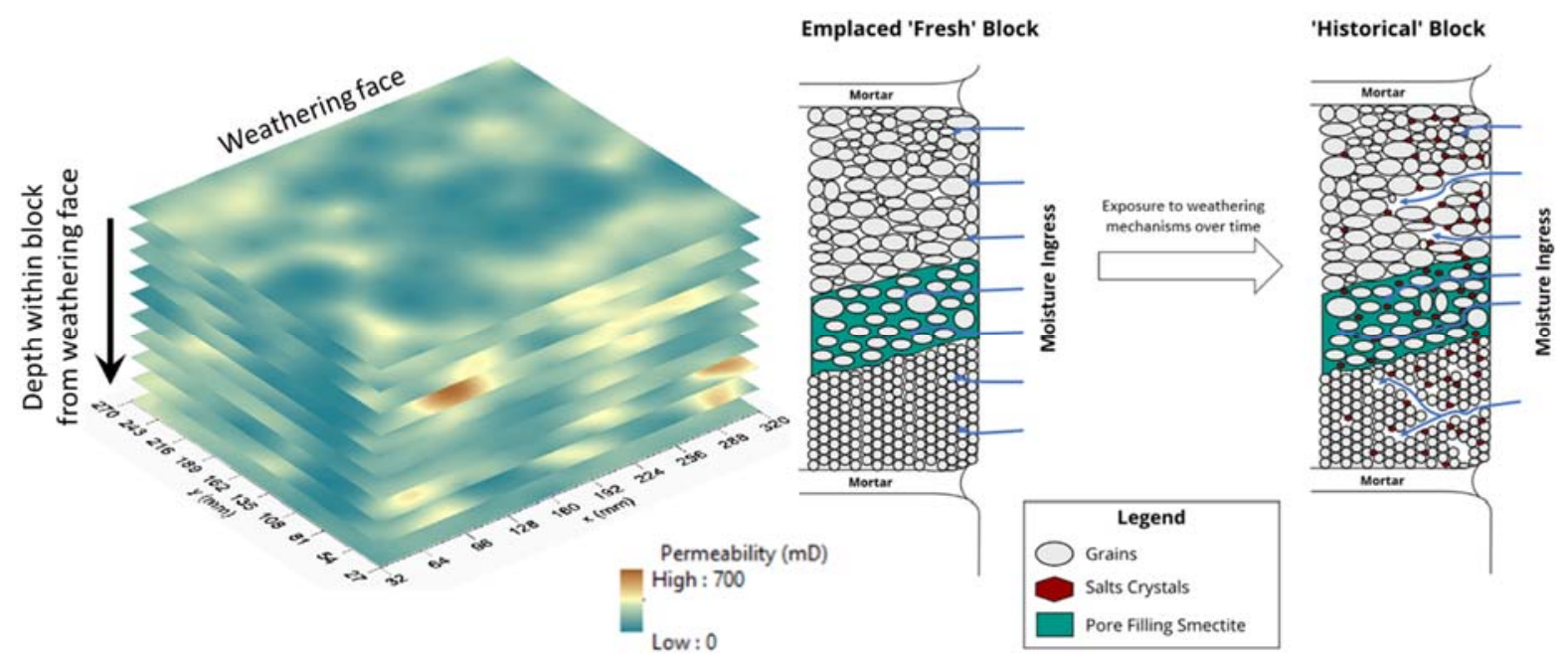

Figure 8. The action of past weathering mechanisms upon the historical block created preferential pathways through the material. The combination of weathering mechanisms, altering permeability resulted in the development of heterogeneous surfaces.

The historical block shows the legacy of continuous exposure to the polluted marine environment of Belfast for the last century. Unlike the 'fresh' block, the limited variety of variogram range values suggests the presence of structures at the scale of the single block. The variance resulting from quarry scale depositional structures has been overwritten by 'new' block scale structures created by weathering processes. This matches with similar observations of structural change during weathering 
simulation cycles by McCabe et al (2011). However, the influence of the sedimentary structures has not been wiped out as evidenced by the oscillation of variance values about the sill, associated with sedimentary periodicity (Webster and Oliver 2007; Jensen et al. 1996). Sedimentary features may also exist at different scales than the measurement scale, either at a finer scale than observations or at a larger scale than the block. Their presence is masked however by the dominant block scale structure of weathering legacy. Zones of higher permeability resulting from pore widening and areas with lower permeability influenced by pore blocking have shaped the material's spatial variability.

The most prominent feature in this estimated surface is not however the presence of an area of higher permeability, but rather the existence of a band of low permeability, corresponding to the presence of a bedding feature. Despite this low permeability, examination of the distribution of the salts through the ion chromatography reveals that this band is also the location of greatest salt accumulation (Figure 9). A likely reason for this localised concentration of salts is the nature of the clays present within the bedding plane. The most common clay in Scrabo sandstone is smectite (Saponite), a material with hygroscopic properties (McKinley et al 2001). This readiness to uptake water, has likely allowed the bedding feature to act as a pathway for salts in solution to ingress from the exposed front to the rear of the block (Figure 8). 

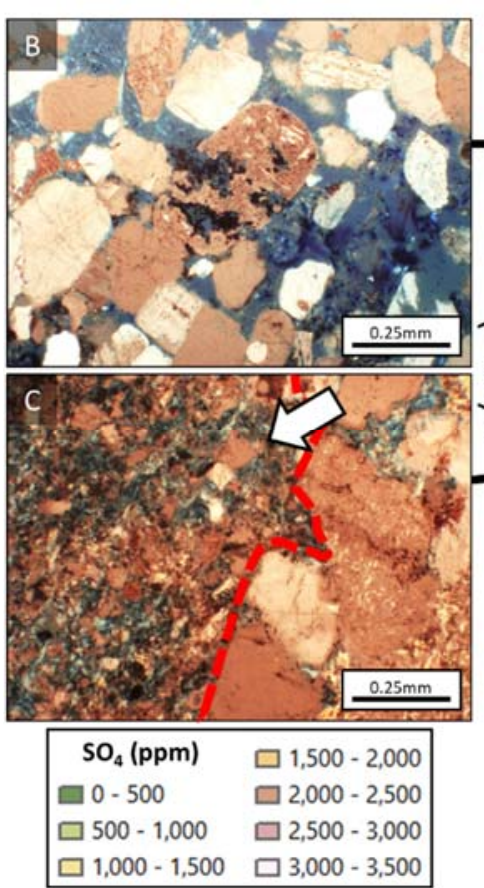

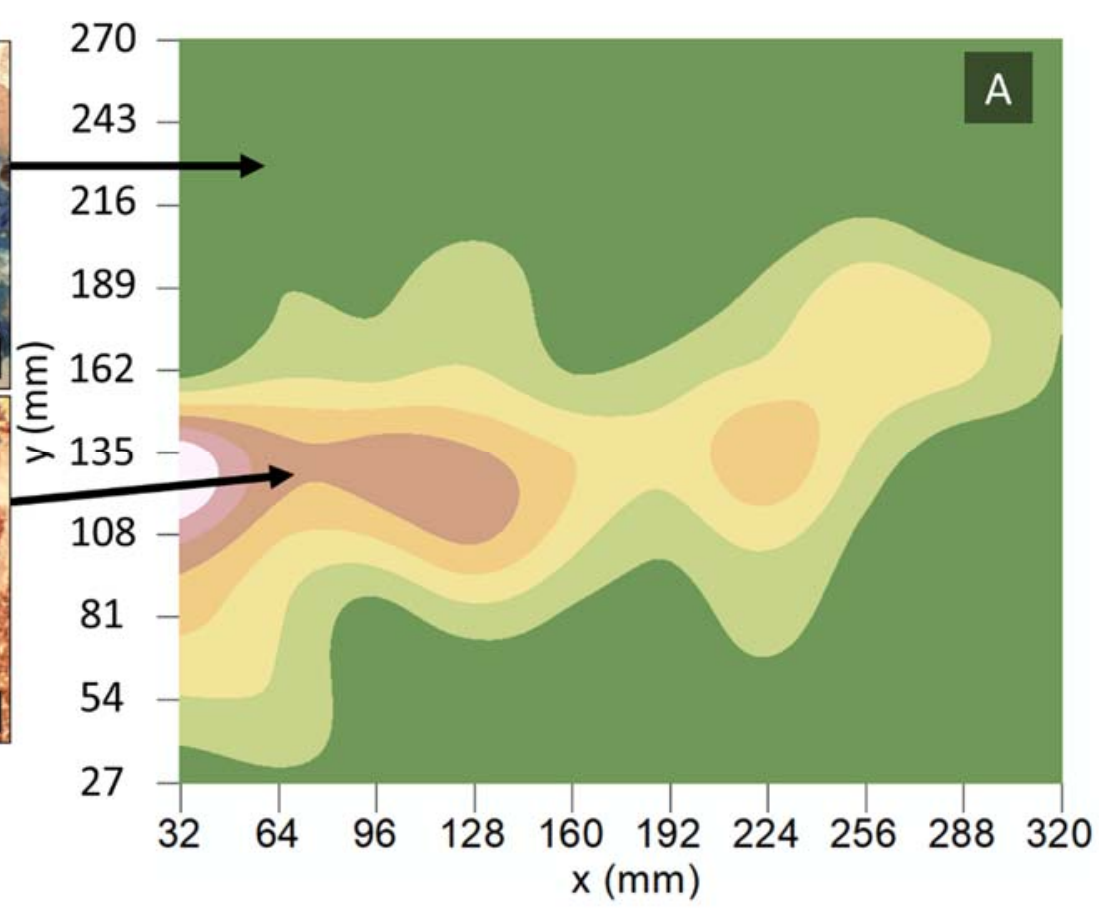

Figure 9. (A) Distribution of Sulphate $\left(\mathrm{SO}_{4}\right)$ in slice 4 of the historical block. Thin sections of the marked locations show, B) the breakdown of quartz grains and filling of pores with salts and C) the accumulation of salts amongst the pore filling smectite within the demarked area of the thin section.

\subsection{Use of Co-Kriging for Conduit Identification}



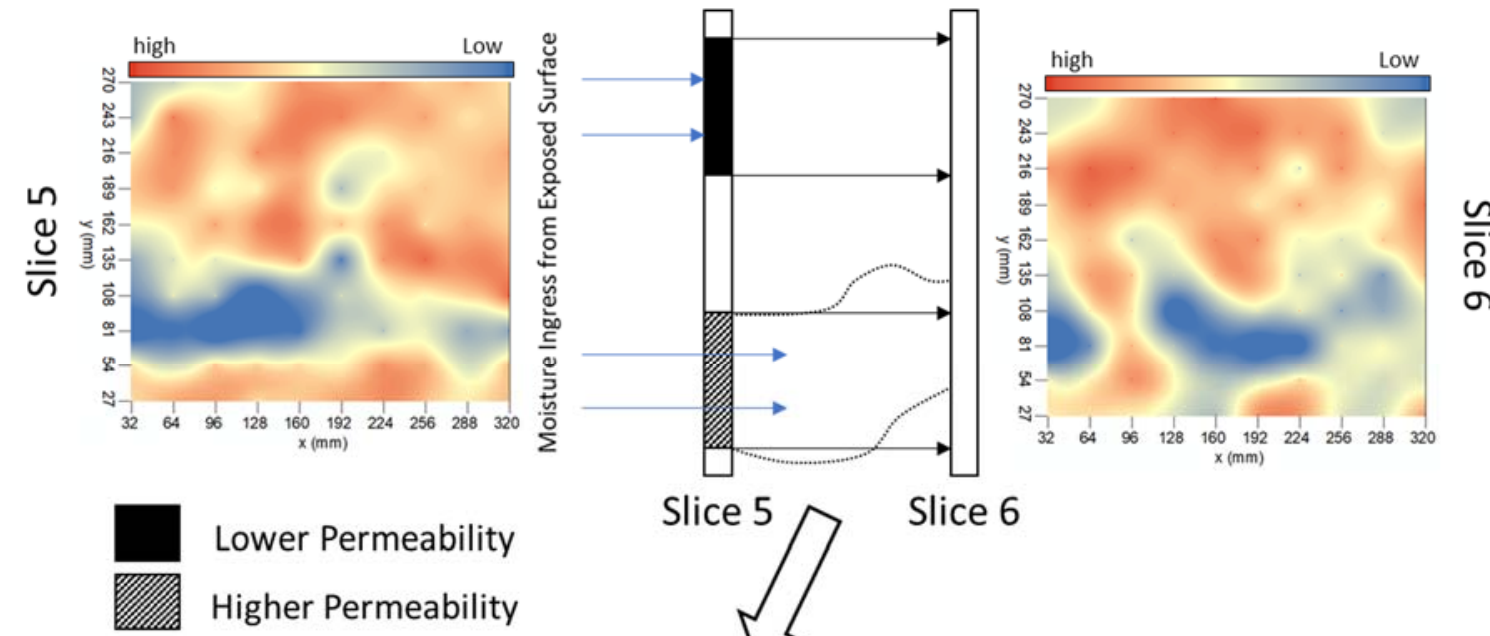

Lower Permeability

Higher Permeability

The resultant cokriged surfaces aid in the visualisation of the presence of possible conduits.
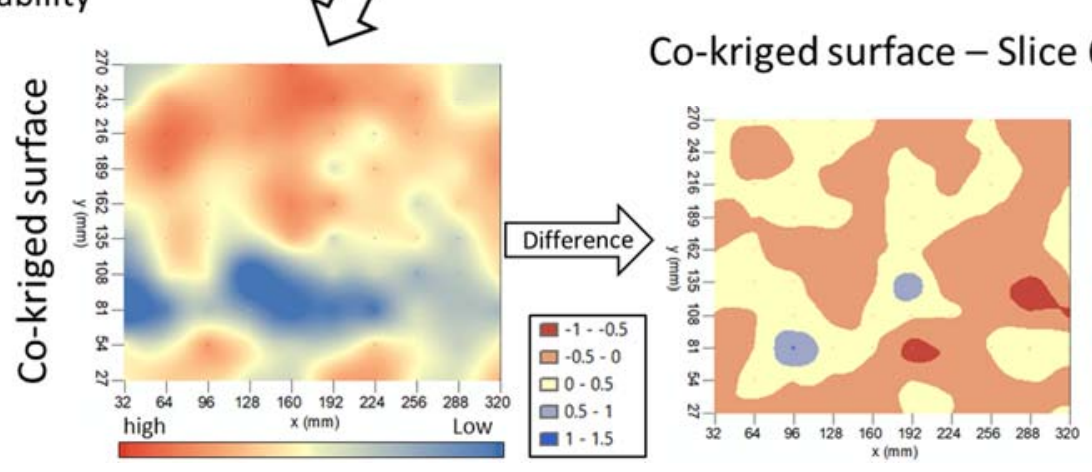

Figure 10. Example generated co-kriged surface, showing where permeability information from two adjacent slices of the historical block indicating the precedence of interconnectivity. Calculating the difference between this kriged surface and slice 6 surface identifies the areas were higher permeability is closest to the weathering front

Cross variogram models have been demonstrated to be effective tools in examining the coregionalisation of properties between the slices of the block. The application for co-kriging can aid in the identification of conduits of moisture ingress between slices as has been observed here (Figure 10). The creation of areas of high permeability throughout the block creates structural inheritance features that can facilitate future ingress and decay. Understanding the spatial correlation of these features between the slices provides an important perspective on the understanding of moisture migration and attempts to predict the future decay pathways.

\subsection{Limitations of the work}


This study shows a significant process in the alteration of networks of permeability throughout a sandstone block due to urban exposure. However, it needs to be noted that the limited availability of sample blocks, both from historical buildings and from the source quarry, which is now closed, means that there is limited opportunity to repeat this form of analysis on this particular stone type. This remains a challenge for all studies into the structural legacy of past weathering of stone.

\section{Conclusions}

Geostatistical approaches have proven to be important tools in the investigation of the spatial variability of the characteristics of clastic sedimentary rocks. Variogram modelling has been demonstrated to be of value for the interpretation of structures through the spatial variability of permeability. Two main conclusions have been drawn from the examination of the variograms.

- The modelled variograms from the 'fresh' block reveal structures at a scale that is larger than the block, suggestive of the sedimentary structures, as observed across the quarry face.

- Alteration of the sandstone's permeability has led to the creation of new weathering related structures within the stone, overwriting the initial sedimentary structures.

Furthermore, co-kriging has been demonstrated as a useful technique for identifying the presence of conduits for the passage of moisture through the block. The findings from this research can be used to inform future predictive models of pathway development through the subsurface material of weathering blocks.

These conclusions and the techniques that have developed them will assist in forming an improved comprehension of weathering legacies within the built environment. Additionally, the application of this quantitative analytical approach may also be of value in the interpretation of the spatial variance of deterioration features in natural stone outcrops.

\section{Acknowledgements}


The authors would like to acknowledge the EPSRC funded project (EP/E049648/1) through which the data used in this analysis was collected. For providing the samples used in this study, we would like to thank both CONSARC for the historical stone sample and the NIEA for the quarry fresh material. The International Association of Mathematical Geoscience (IAMG) is acknowledged for an IAMG student grant that funded the lead author's attendance and presentation of this research at the IAMG2017 conference, Perth, Western Australia. The feedback from this conference enabled validation of the geostatistical methodology and the refining of the research approach for this work. The authors also gratefully acknowledge the constructive comments from the reviewers of an earlier version of this work. 


\section{References}

André, M., Phalip, B., Voldoire, O., Vautier, F., Géraud, Y., Benbakkar, M., Constantin, C., Huber, F., Morvan, G., 2011. Weathering of sandstone lotus petals at the Angkor site: A 1,000-year stone durability trial. Environ. Earth Sci. 63(7), 1723-1739.

Angeli, M., Benavente, D., Bigas, J., Menéndez, B., Hébert, R., David, C., 2008. Modification of the porous network by salt crystallization in experimentally weathered sedimentary stones. Mater. Struct. 41(6), 1091-1108.

Beggan, J., Long, A., Basheer, P., 1996. The permeability testing of masonry materials. In: Smith, B., Warke, P. (Eds.), Processes of Urban Stone Decay. Donhead, London, pp. 205-211.

Benavente, D., García del Cura, M., Bernabéu, A., Ordóñez, S., 2001. Quantification of salt weathering in porous stones using an experimental continuous immersion method. Eng. Geol. 59, 313 - 325.

BERG, 1989. The Effects of Acid Deposition on Buildings and Building Materials. HMSO, London.

Buckman, J., Doughty, P., Benton, M., Jeram, A., 1997. Palaeoenvironmental Interpretation of the Triassic Sandstones of Scrabo, County Down, Northern Ireland: Ichnological and Sedimentological Studies Indicating a Mixed Fluviatile-Aeolian Succession. Irish J. Earth Sci. 16, 85-102.

Buj, O., Gisbert, J., McKinley, J., Smith, B., 2011. Spatial characterization of salt accumulation in early stage limestone weathering using probe permeametry. Earth Surf. Proc. Land. 36(3), 383-394.

Carey, P., Curran, J., 2000. High-resolution characterisation of permeability in arenaceous building stones. Z. Geomorphol. Supp. 120, 175-185.

Cooke, R., Gibbs, G., 1995. Crumbling Heritage? Studies of Stone Weathering in Polluted Atmospheres. National Power, London. 
Corbett, P., Jensen, J., 1993. Quantification of variability in laminated sediments: a role for the probe permeameter in improved reservoir characterisation. In: North, C., Prosser, D. (Eds.), Characterisation of Fluvial and Aeolian Reservoirs, Geological Society Special Publication No. 73. pp. 433-442.

Curran, J., Warke, P., Stelfox, D., Smith, B., Savage, J., 2010. Stone by Stone: A guide to Building Stone in the Northern Ireland Environment. Appletree Press, Belfast.

Di Benedetto, C., Cappelletti, P., Favaro, M., Graziano, S.F., Langella, A., Calcaterra, D., Colella, A., 2015. Porosity as key factor in the durability of two historical building stones: Neapolitan Yellow Tuff and Vicenza Stone. Eng. Geol. 193, 310-319.

Doehne, E., 2002. Salt weathering: a selective review. In Přikryl, R., Smith, B. (Eds.), Geological Society Special Publications No. 205. pp. 51-64.

Fitzner, B., 1990. Porosity Analysis: A Method for the Characterisation of Building Stones in Different Weathering States. In: Marinos, P., Koukis, G. (Eds.), Engineering Geology of Ancient Works, Monuments and Historical Sites. Balkema, Rotterdam, pp. 2031-2037.

Fitzner, B., Heinrichs, K., 2002. Damage diagnosis at stone monuments - Weathering forms, damage categories and damage indices. In: Přikryl, R., Viles, H. (Eds.), Understanding and Managing Stone Decay. The Karolinum Press, Prague, pp. 11-58.

Goggin, D., 1993. Probe Permeametry: is it worth the effort? Mar. Petrol. Geol. 10, 299-308.

Gomez-Heras, M., McCabe, S., 2015. Weathering of stone-built heritage: A lens through which to read the Anthropocene. Anthropocene 11, 1-13.

Gomez-Heras, M., McCabe, S., Smith, B., Fort, R., 2009. Impacts of Fire on Stone-Built Heritage. J. Archit. Conserv. 15(2), 47-58. 
Goudie, A., 2016, Quantification of rock control in geomorphology. Earth Sci. Rev. 159, 374-387.

Goudie, A., Viles, H., 1997. Salt Weathering Hazards. Wiley \& Sons, Chichester.

Grover, D., Savidge, C. Townsend, L. Rosario, O., Hu, L., Rizzo, D., Dewoolkar, M., 2016. Surface Permeability of Natural and Engineered Porous Building Materials. Constr. Build. Mater. 112, 1088-1100.

Inkpen, R., 1991. Stone weathering and the 'memory' effect. Department of Geography, Portsmouth Polytechnic, Working Paper No.17.

Inkpen, R., Petley, D., Murphy, W., 2004. Durability and Rock Properties. In: Turkington, A., Smith, B. (Eds.), Stone decay: Its causes and controls. John Wiley \& Sons Ltd., Chichester, pp. 149-166.

Jensen, J., Glasbey, C., Corbett, P., 1994. On the Interaction of Geology, Measurement and Statistical Analysis of Small-Scale Permeability Measurements. Terra Nova 6, 397-403.

Jensen, J., Corbett, P., Pickup, G., Ringrose, P.S., 1996. Permeability semivariograms, geological structure, and flow performance. Math. Geol. 28(4), 419-435.

Jones, S., 1994. A new, fast, accurate pressure-decay probe permeameter. SPE Formation Evaluation 9(3), 193-199.

Kerry, R. and Oliver, M., 2007 Determining the effect of asymmetric data on the variogram. I. Underlying asymmetry. Comput. Geosci. 33(10), 1212-1232.

McCabe, S., Smith, B., Warke, P., 2007. Preliminary Observations on the impact of complex stress histories on sandstone response to salt weathering: laboratory simulations of process combinations. Eng. Geol. 52, 251-258. 
McCabe, S., McKinley, J., Gomez-Heras, M., Smith, B., 2011. Dynamical instability in surface permeability characteristics of building sandstones in response to salt accumulation over time. Geomorphology 130(1), 65-75.

McCabe, S., McAllister, D., Warke, P., Gomez-Heras, M., 2015. Building Sandstone Surface Modification by Biofilm and iron Precipitation: Emerging Block Scale heterogeneity and system response. Earth Surf. Proc. Land. 40(1), 112-122.

McKinley, J., Warke, P., 2007, Controls on Permeability: Implications for Stone Weathering. In: Prikryl, R., Smith, B. (Eds.), Building Stone Decay: from Diagnosis to Conservation, Geological Society Special Publication No. 271, pp. 225-236.

McKinley, J., McCabe, S., 2010. A Geostatistical Investigation into Changing Permeability of Sandstones During Weathering Simulations. Geogr. Anal. 42(2), 180-203.

McKinley, J., Worden, R., Ruffell, A., 2001. Contact diagenesis: The effect of an intrusion on reservoir quality in the Triassic Sherwood sandstone group, Northern Ireland. J Sediment Res 71(3), 484495.

McKinley, J. Lloyd, C., Ruffell, A., 2004. Use of Variography in Permeability Characterization of Visually Homogeneous Sandstone Reservoirs with Examples from Outcrop Studies. Math. Geol. 36(7), 761-779.

McKinley, J., Warke, P., Lloyd, C., Ruffell, A., Smith, B., 2006. Geostatistical Analysis in Weathering Studies: case study for Stanton Moor Building Sandstone. Earth Surf. Proc. Land. 31(8), 950-969.

McKinley, J., Atkinson, P., Lloyd, C., Ruffell, A., Worden, R., 2011. How Porosity and Permeability Vary Spatially with Grain Size, Sorting, Cement Volume, and Mineral Dissolution in Fluvial Triassic Sandstones: The Value of Geostatistics and Local Regression. J. Sediment. 81(12), 844-858. 
McKinley, J., Ruffell, A., Worden, R., 2012. An integrated Stratigraphic, petrophysical, geochemical and geostatistical approach to the understanding of burial diagenesis: Triassic Sherwood Sandstone Group, South Yorkshire, UK. In: Morad, S., Ketzer, J., De Ros, L. (Eds.), Linking Diagenesis to Sequence Stratigraphy. Wiley-Blackwell, Chichester, pp. 231-256.

Muir, C., 2006. Sandstone. In: Henry, H. (Ed.), Stone Conservation: Principles and Practice. Donhead, Aberdeen, pp. 191-215.

Oliver, M., Webster, R., 2015. Basic Steps in Geostatistics: The variogram and Kriging. Springer, London.

Oliver, M. and Webster, R., 2014. A tutorial guide to geostatistics: Computing and modelling variograms and kriging. Catena, 113, pp.56-69.

Pebesma, E., 2004. Multivariable geostatistics in S: the gstat package. Comput. Geosci. 30, 683-691.

Pope, G., 2002. Geomorphology's role in the study of weathering cultural stone. Geomorphology 47, 211-225.

Pope, G., Rubenstein, R., 1999. Antroweathering: Theoretical Framework and casework for humanimpacted weathering. Geoarchaeology 14(3), 247-264.

Smith, B., Magee, R., Whalley, W., 1994. Breakdown Patterns of Quartz Sandstone in a polluted Urban Environment, Belfast, Northern Ireland. In: Robinson, D., Williams, R. (Eds.), Rock Weathering and Landform Evolution. John Wiley \& Sons Ltd., Chichester, pp. 131-150.

Smith, B., Turkington, A., Warke, P., Basheer, P., McAlister, J., Meneely, J., Curran, J., 2002. Modelling the Rapid Retreat of Building Sandstones: A Case Study from a polluted Marine Environment. In: Siegesmund, S., Weiss, T., Vollbrecht, A. (Eds.), Natural Stone, Weathering Phenomena, 
Conservation Strategies and Case Studies: Geological Society Special Publication No. 205, pp. $347-362$

Smith, B., Turkington, A., Curran, J., 2005. Urban stone decay: The great weathering experiment? In: Turkington, A. (Ed.), Stone decay in the architectural environment: Geological Society of America Special Paper 390, pp. 1-9.

Smith, B., Gomez-Heras, M., McCabe, S., 2008. Understanding the decay of stone-built cultural heritage. Prog. Phys. Geog. 32(4), 439-461.

Smith, I., 1991. Geology of the County around Newtonards. HSMO, Belfast.

Summerfield, M., 2013. Global Geomorphology. Routledge, Oxon.

Turkington, A., 1996. Stone Durability. In: Smith, B., Warke, P. (Eds.), Processes of Urban Stone Decay. Donhead, Aberdeen, pp. 32-46.

Turkington, A., Smith, B., 2004. Interpreting the spatial complexity of decay features on the sandstone wall: St. Mattew's Church, Belfast. In: Turkington, A., Smith, B. (Eds.), Stone decay: Its causes and controls. John Wiley \& Sons Ltd., Chichester, pp. 149-166.

Turkington, A., Paradise, T., 2005. Sandstone weathering: A century of research and innovation. Geomorphology 67, 229-253.

Viles, H., 2005. Can Stone Decay be Chaotic? In: Turkington, A. (Ed.), Stone Decay in the Architectural Environment: Geological Society of America Special Paper 390. GSA: Boulder, pp. 11-16.

Warke, P., 1996. Inheritance effects in building stone decay. In: Smith, B., Warke, P. (Eds.), Processes of Urban Stone Decay. Donhead, Aberdeen, pp. 32-46. 
Warke, P., Smith, B., 2000. Salt Distribution in clay-rich weathered sandstone. Earth Surf. Proc. Land. 25(12), 1333-1342.

Warke, P., McKinley, J., Smith, B., 2006. Variable weathering response in sandstone: factors controlling decay sequences. Earth Surf. Proc. Land. 31(6), 715-735.

Webster, R., Oliver, M., 2007. Geostatistics for Environmental Scientists. Wiley \& Sons, Chichester.

Yatsu, E.,1988. Weathering: An Introduction. Overseas distributor Maruzen Co, Osaka.

Zhao, S., Zhou, Y., Wang, M., Xin, X., Chen, F., 2014. Thickness, porosity, and permeability prediction: comparative studies and application of the geostatistical modelling in an Oil field. Env. Sys. Res. 3(7), 1-24. 